\title{
5. Circulação de cerâmica romana na Hispânia
}

\author{
Rui Morais \\ Universidade do Porto \\ rmorais@letras.up.pt
}

Centro de Estudos Clássicos e Humanísticos

ORCID: 0000-0002-5052-7164

\begin{abstract}
Sumário: A cerâmica romana como fonte de informação cultural, social, económica e tecnológica. Breve panorama sobre a presença das cerâmicas no contexto da conquista e da ocupação romana na Hispânia. Os estudos e as principais categorias de cerâmicas romanas conhecidas.
\end{abstract}

\section{As cerâmicas: os materiais mais usados na vida diária...}

As cerâmicas estão entre os materiais arqueológicos mais significativos pelo fato de proporcionarem dados crono-tipológicos e ocuparem um lugar incomparável como fontes de informação cultural, social, económica e tecnológica, e permitirem uma visão do passado mais completa e documentada possível. São fósseis diretores de maior importância, fundamentais para o conhecimento da história das civilizações pretéritas. Mas, como proclamava Nino Lamboglia (1950), o seu estudo não deve ser um fim em si mesmo, mas antes um meio ao serviço do progresso científico. As questões que se colocam são variadas, pois a presença maciça destes materiais nos registos arqueológicos e o modo como aparecem são alguns dos problemas com que se deparam os arqueólogos. $\mathrm{O}$ achado ou ausência de determinados tipos de cerâmica, assim como a frequência em que aparecem, permitem extrair uma série de dados arqueológicos suscetíveis de proporcionar uma informação histórica muito importante. As cerâmicas destinavam-se a satisfazer a procura e a competir com outros materiais como a madeira, o vidro e o metal.

A presença romana na península a partir de finais do século III a.C. levou à mudança de hábitos alimentares e de consumo que se repercutiram no panorama das cerâmicas. Apesar da produção oleira romana se caraterizar pela padronização, casos houve em que se mantiveram as tradições peninsulares, quer 
ao nível formal, quer nas modalidades decorativas, como sucedeu com algumas cerâmicas pintadas ainda fortemente influenciadas pelas tradiçôes ibéricas, de que nos servem de exemplo as produçôes augustanas de Ilici. Simultaneamente, alteram-se algumas tradições oleiras e criaram-se novos centros produtores, como se documenta em Lugo, Braga, Leão, Irún, La Rioja, Saragoça, Barcelona, Tarragona, Ampúrias, Valencia, Alicante, Cartagena, Cádis, Sevilha, Granada, Córdova, Mérida, Segóbriga, Beja, Lisboa, Santarém, Conimbriga....

No tema em análise, sobre a circulação das cerâmicas romanas na Hispânia, podemos destacar algumas problemáticas de especial interesse. Este é o caso das produçôes de âmbito militar, como as do acampamento da legio III Macedonica, em Herrera de Pisuerga. Aí trabalhou um figlinarius, chamado $L$. Terentius, que assinou formas lisas de terra sigillata local de tradição itálica com o seu nome, acrescentando-lhe a referência da respetiva unidade militar. Escavações realizadas na cidade de Leão, nos níveis correspondentes ao do acampamento da legio VI vitrix, permitiram dar a conhecer outro ambiente produtor de terra sigillata local de tradição itálica. O nome mais bem documentado é o de C. Licinius Maximus, ainda que se conheça o nome de outros oleiros ${ }^{1}$. Igualmente interessante é a questão da migração de artesãos na Hispânia que teria implicado a abertura de verdadeiras sucursais e permitido uma maior difusão das tradições e técnicas oleiras. Uma das consequências deste fenómeno foi, muito provavelmente, a celebração de contratos jurídicos (de tipo locatio-conductio) entre as oficinas produtoras de cerâmicas e as cidades ou províncias. Este parece ter sido o caso documentado nas cidades romanas de Bracara Augusta (Braga) e de Caesaraugusta (Saragoça) ${ }^{2}$.

\section{Cerca de mil anos de consumo...}

O estudo da circulação de cerâmica romana na Hispânia deve levar em consideração duas questôes intimamente relacionadas: a cronologia das produçôes em si mesmas e as datas atribuídas a partir de contextos de utilização e abandono. No primeiro caso, a finalidade principal é aquela de atribuir um valor cronológico de acordo com as mudanças técnicas, formais e decorativas. No segundo caso, deve considerar-se a análise da estratigrafia através

\footnotetext{
${ }^{1}$ Todavia, ao contrário do que aconteceu com L. Terentius, estamos possivelmente perante libertos de condição civil que trabalharam para abastecer, quer o corpo militar aqui estabelecido, quer a população civil assentada nas canabae. No momento em que terminam as produçóes de Terentius nos finais do período de Augusto, dá-se o início da produção de Licinius que perdurará pelo menos durante o reinado de Tibério (Morillo \& Garcia Marcos 2001 155; Morillo 2006 44; 2008 275-293).

${ }^{2}$ Este tipo de contactos, bem conhecidos em papiros encontrados no Egito, pressupunha que as cidades ou províncias ocupariam o papel de locator, arrendando um terreno público ou locais de extração das argilas a um officinatorl conductor.
} 
do estabelecimento de sequências relativas atribuindo-lhes uma datação. Por vezes, este estudo é dificultado pela duração de vida das cerâmicas, pela sua raridade ou por aspetos intrusivos pós-deposicionais.

Em síntese, podemos dizer que as produçōes de cerâmica romana se distribuem por um lato período de tempo que abarca cerca de mil anos, desde o final do século III a.C., com a chegada dos exércitos romanos no início da Segunda Guerra Púnica, até um momento avançado do século VII d.C. que termina com a chegada das últimas produções de cerâmicas finas, de cozinha e de ânforas, provenientes de África (em particular da zona tunisina) e do Oriente (Fócida, ilhas do Egeu, Chipre, Síria, Palestina e Egito). Saliente-se, no entanto, que grande parte das produções romanas começam a decair no último quartel do século $\mathrm{V}$ d.C., data coincidente com a ocupação dos Visigodos da última província romana da Hispânia, a Tarraconense, apenas alguns anos antes da queda do Império Romano do Ocidente em 476 d.C..

\section{Os estudos sobre cerâmica na Hispânia}

A bibliografia especializada tem aumentado exponencialmente nos últimos anos, sob a forma de guias de cerâmica, de grandes sínteses, de monografias, de simples catálogos e notícias, devedores de escolas e tendências de investigação e de mentalidades distintas. Acrescem ainda os estudos laboratoriais dedicados à caracterização mineralógica e físico-química das pastas e dos resíduos orgânicos obtidos por cromatografia gasosa com espectrometria de massa, estes últimos fundamentais para o reconhecimento dos conteúdos orgânicos conservados na porosidade das argilas e para um melhor conhecimento da alimentação no mundo antigo.

Os primeiros estudos sobre cerâmica romana na Hispânia remontam ao século XIX, ainda que escassos, e irão aumentar progressivamente a partir de meados do século XX. Refira-se, a título de exemplo, o volume editado a propósito da mesa redonda sobre cerâmica de Conimbriga: À propos des céramiques de Conimbriga (1976) e os volumes das Fouilles de Conimbriga sobre as cerâmicas. Como apoio dos jovens investigadores e arqueólogos foi fundamental a publicação, em 1978, da obra "Cerâmica romana. Tipología y clasificación" de Miguel Beltrán Lloris, atualizada e ampliada no "Guía de la cerâmica romana", em 1990.

Para o estudo dos modos de produzir a cerâmica têm-se recorrido a estudos etnoarqueológicos. A este respeito refiram-se as obras de D. P. S. Peacock (em particular, 1982) que elaborou uma série de modelos produtivos através de uma leitura de tipo económico de casos etnográficos e arqueológicos.

Nas primeiras décadas do presente século, verificou-se um aumento exponencial dos estudos sobre cerâmica romana, situação que impulsionou a criação de uma associação de estudos denominada "Sociedad de Estudios de la Cerámica Antigua en Hispania” (SECAH), criada em 2009, e que já organizou, para além de cursos, excursōes e conferências, quatro congressos internacionais, ocorridos em Cádis 
(2011); em Braga (2013); em Tarragona, (2014); e em Valência (2017). Entre outras obras publicadas, algumas das quais resultantes de congressos e de cursos de formação de arqueólogos em Alcalá de Henares, salientem-se ainda dois livros intitulados Cerámicas Hispanorromanas, dedicados às produçôes cerâmicas romanas na Hispânia (Bernal e Ribera 2008 e 2012) e as monografias publicadas no âmbito dos "Cursos de Formación Permanente para Arqueólogos" organizado pelo "Museo Arqueológico Regional de la Comunidad de Madrid" e o "Colegio de Doctores y Licenciados em Filosofia y Letras y en Ciencias de la Comunidad de Madrid".

\section{As principais categorias cerâmicas}

O estabelecimento e consagração das principais categorias cerâmicas - "campanienses", "sigillatas", "paredes finas", "lucernas", "ânforas", "cerâmicas comuns" (incluindo as variedades pintadas e as engobadas de vermelho ou branco), etc., - permite-nos atentar num estudo global sobre a sua circulação na Hispânia. Regra geral, o estudo das cerâmicas por categorias e, consequentemente, a formulação de quadros sinópticos e tipológicos deve levar em consideração a conjugação de aspetos relacionados com a cronologia, produção, proveniência, função, distribuição, transporte, consumidores, conhecimentos técnicos, etc..

Nesta exposição, por uma questão de método, torna-se necessário apresentá-las separadamente pelas categorias acima referidas de modo a permitir ao leitor reconstituir e inferir as relaçôes de contemporaneidade de algumas destas produções, bem como o seu tempo de vida funcional e os circuitos comerciais em que estiveram inseridas. Alerta-se, todavia, que estas produções não devem ser estudadas isoladamente mas antes integradas nos respetivos contextos arqueológicos e em direta relação com as sequências estratigráficas relativas e associadas a outros elementos da cultura material, como os vidros, os metais e as moedas, ou mesmo aos restos faunísticos, de modo a determinar a natureza dos contextos.

As diferentes categorias cerâmicas acima enunciadas podem ser incluídas em três grandes grupos funcionais: baixelas finas de mesa, contentores de transporte, utensílios de cozinha, à parte, naturalmente, de outros grupos mais especializados, como as candelas e as lucernas ou as miniaturas e os materiais de construção.

No âmbito da difusão das cerâmicas romanas na Hispânia é usual distinguirse as produções destinadas a um comércio interprovincial e provincial daquelas produzidas para consumo regional e local, com difusão mais reduzida. Devem ainda considerar-se as cerâmicas importadas de outras regiōes do império, difundidas na Hispânia a partir das zonas costeiras, por via marítima e fluvial, ainda que naturalmente usufruíssem de uma redistribuição por via terrestre, acompanhando outras mercadorias. De modo a estudar estas distintas realidades pode recorrer-se a mapas de distribuição, apesar do maior ou menor grau de precisão que estes possam apresentar. Estes mapas devem, sempre que possível, fazer referência a valores percentuais das diferentes categorias de cerâmica (ou 
diferentes tipos dentro de cada categoria) e compará-los com mapas de outros sítios. Tal tarefa poderá permitir estudar a modalidade de distribuição em função da distância relativamente ao(s) centro(s) de produção, e considerar, separadamente, as vias terrestres e aquáticas (fluviais e marítimas).

\section{Breve enquadramento sobre a circulação da cerâmica romana na Hispânia}

As cerâmicas romanas na Hispânia apresentam pautas de difusão muito distintas. Após uma presença das cerâmicas áticas ao largo dos séculos VI a IV a.C., dá-se uma substituição destas pelas baixelas campanienses de produção itálica ${ }^{3}$ (e suas imitações) que se difundem de forma paulatina a partir de finais do século III a.C. na costa levantina e que rapidamente invadem toda a península, em particular as zonas costeiras. Estas cerâmicas, caracterizadas por possuir um engobe negro mais ou menos brilhante, eram produzidas em série para serem comercializadas por via marítima, como se evidencia pelo repertório formal, que se restringe aos tipos abertos (pratos, copos e variantes), mais fáceis de empilhar nas embarcaçóes.

A partir de meados do século I a.C. temos a presença de outras baixelas finas de mesa também provenientes da Península Itálica, conhecidas por terra sigillata ${ }^{4}$. Numa primeira fase estas produçôes acompanham os exércitos e os comerciantes que os seguiam, mas rapidamente se difundem por toda a Hispânia. Cumprindo os requisitos do gosto da época, adotam-se novos métodos de cozedura, passando agora estas cerâmicas a ter um engobe vermelho/acastanhado, em substituição do engobe negro das cerâmicas anteriores. A par das produções lisas de terra sigillata junta-se, por volta do ano 15 a.C., a criação de uma produção decorada com motivos em relevo, obtida por meio de moldes, segundo um procedimento já utilizado na cerâmica de Mégara, o que confere ao repertório decorativo destas produçôes uma extraordinária qualidade nos relevos e uma maior padronização. As formas correspondem às necessidades da mesa: fabricavam-se verdadeiros serviços em que predominam os pratos e as taças para consumo de alimentos e bebidas. Na Hispânia, a maior parte destas produções itálicas provém de Arécio, seguidas pelas produções de Pisa, Putéolos e do Vale do Pó. Como se documenta pela difusão destas cerâmicas, bem cedo a produção e exportação atingiram

${ }^{3} \mathrm{Na}$ península itálica, onde estas cerâmicas são originárias, conhecem-se diferentes produçōes, de acordo com os centros de fabrico e as características morfológicas (sobre este assunto ver Morais 2012 95-96).

${ }^{4}$ Este termo latino foi adotado pelos eruditos modernos e aplicado a vasos feitos em moldes, lisos ou decorados com figuras em relevo (sigilla) e, por extensão, a toda a cerâmica fina de mesa de superfície vermelha e brilhante da época imperial. Neste breve excurso não nos vamos referir à chamada terra sigillata Oriental $\mathrm{A}$, pois, apesar de uma especial concentração na zona sudeste da península (em particular nos finais do século II e os inícios do século I a.C.), não teve uma especial difusão na Hispânia. 
dimensões consideráveis, à semelhança da já referida cerâmica campaniense. Mas, contrariamente a esta, a terra sigillata itálica não é uma mercadoria anónima: frequentemente se imprimia a marca, quer no fundo interno dos vasos lisos, quer nos moldes das peças decoradas. A marca era a do oleiro que fabricava a peça (homem livre ou escravo) ou a do proprietário da oficina. $\mathrm{Na}$ península ibérica esta cerâmica teve uma ampla difusão, especialmente nas áreas costeiras, mas também se encontra em número considerável em áreas interiores da meseta norte, em concreto nos acampamentos militares de Herrera de Pisuerga, Astorga e Leão (Perez Gonzalez 1989). As vantagens comerciais da terra sigillata itálica impulsionaram a criação de sucursais nas províncias, como a de Ateius em La Muette (Lyon, França), e, inclusivamente, a criação de produções regionais em âmbitos militares (como foi o caso de L. Terentius, em Herrera de Pisuerga) ou civis (em especial a cerâmica bética de "tipo Peñaflor"), que devem ser conceptualmente designadas pelo termo de "terra sigillata local de tradição itálica".

A partir de finais do período de Augusto e durante o reinado de Tibério, dá-se uma mudança nos registos arqueológicos: a terra sigillata itálica vai sendo paulatinamente substituída por produções do sul da Gália, oriundas de centros como La Graufesenque, Montans e Banassac. A terra sigillata gálica, sobretudo a de La Graufesenque, invade os mercados peninsulares, sendo particularmente abundante nas áreas costeiras. Seguem-se, em número, as produções de Montans, bem difundidas na parte nordeste da península. Menos abundantes são as produçôes de Banassac, ou mesmo os produtos provenientes de centros produtores do centro da Gália, como o caso de Lezoux.

Mas, depois de um período de auge nos meados do século I d.C., a difusão de terra sigillata do sul da Gália decai. Este momento coincide com a ascensão das sigillatas hispânicas, cujos maiores centros de produção estão documentados na Tarraconense, em Tritium Magallum, e na Bética, em Isturgi (Andújar, Jáen) e Granada, com um auge de produção no último quartel do século I e um período de decadência no decorrer da primeira metade do século II d.C.. Estas produções difundem-se por toda a Hispânia, mas também alcançaram outros mercados, nomeadamente a região do sudoeste francês, a Grã-Bretanha, a Itália e o Norte de África. Depois de um período de aparente decadência situado no século III d.C. dá-se uma retoma nos sécs. IV a VI d.C., com a chamada terra sigillata hispância tardia (TSHT) produzida nos vales dos rios Ebro e Douro.

Um último fenómeno de produção e de exportação de terra sigillata a grande escala verificou-se a partir dos finais do século I d.C., e de forma intensiva sobretudo entre os séculos III e V d.C., na África Proconsular, e, em particular, na área coincidente com a atual Tunísia. A produção africana inclui vasos de mesa, lisos ou decorados, sendo as decorações, por vezes, de excecional requin$\mathrm{te}^{5}$. A produção da cerâmica fina africana, ainda que afetada pelo impacto da

${ }^{5}$ A técnica decorativa de relevos aplicados, conhecida desde o século II d.C., generaliza-se na primeira metade do século IV d.C., ainda que mais desorganizada e repetitiva. 
invasão dos Vândalos, e depois pela conquista bizantina, perdurou ainda no século VII d.C.. Na península temos representadas no registo arqueológico todas estas fases da terra sigillata africana, ainda que naturalmente esta seja mais abundante nos séculos IV e V d.C..

À Hispânia chegaram ainda algumas produçôes tardias de sigillata fabricadas na Gália e no Mediterrâneo oriental. As produçōes gálicas, conhecidas por "dérivées des Sigillées Paléochrétiennes" (DSP) ou simplesmente "sigillatas gálicas tardias", provém de três áreas produtoras: o grupo Provençal (maioritariamente fabricadas na área de Marselha), o grupo Languedocense ou Narbonense (maioritariamente fabricadas em Narbona e em Carcassone) e o grupo Atlântico (com possível centro principal em Bordéus.). Na Hispânia, as duas primeiras produções estão relativamente bem representadas no litoral mediterrânico até o sul da península (em particular aquelas do grupo provençal), seguindo a direção natural norte/sul. As do grupo Atlântico têm uma difusão mais acentuada na costa cantábrica e no sul da Galiza (em particular, Vigo). As produçôes orientais estão particularmente bem representadas pelas chamadas "sigillatas foceenses" (Late Roman C), maioritariamente fabricadas na Fócida (atual Turquia ocidental), entre Esmirna e Pérgamo, de finais do séc. IV d.C. a meados do séc. VII d.C., e da menos abundante produção cipriota (Late Roman $D)^{6}$, do $3^{\circ}$ quartel do séc. IV d.C. a finais do VII ou inícios do VIII d.C.. Como no alto-império, a cronologia rigorosa que pode atribuir-se a estas baixelas finas de mesa faz delas o mais útil instrumento dos arqueólogos para a datação dos sítios que escavam.

Se compararmos os mapas de dispersão das sigillatas africanas (em particular do fabrico D) e foceenses relativamente à da terra sigillata hispânica tardia, constata-se uma presença destacada das duas primeiras ao largo do litoral mediterrâneo, atlântico e cantábrico e, em menor medida, no interior, em particular nas áreas beneficiárias das vias fluviais mais importantes: Guadalquivir, Ebro, Douro e Tejo; como vimos, em situação inversa está a terra sigillata hispânica tardia com uma natural concentração nas áreas de produção dos vales do Ebro e Douro. A sua presença no interior da península está ligada a um peculiar horizonte cultural cujo maior expoente são as uillae e as necrópoles tardo-romanas da Meseta e do curso superior do Ebro.

Para além das sigillatas faziam parte das baixelas finas de mesa as cerâmicas de "paredes finas". Tal designação alude à característica finura da parede (entre 0,5 e $2,5 \mathrm{~mm}$ ) de vasos usados para beber, em particular copos e taças (vasa potoria). Alguns vasos produzidos em oficinas do norte da Itália e do sul da Península Ibérica possuem uma parede particularmente fina, donde o nome de "casca de ovo". As argilas desta cerâmica são muito variáveis e de diferentes graus de depuração, consoante os lugares de produção. É também característico destas

\footnotetext{
${ }^{6}$ Recentemente documentou-se uma zona de produção de Late Roman D nas costas da atual Turquia. A ausência de fornos escavados em Chipre deixa aberta a possibilidade de que esta produção seja originária da zona Turca (Panfília).
} 
cerâmicas o especial tratamento da superfície externa, de acordo com diferentes técnicas: buriladas, incisas, com aplicaçôes arenosas, de tipo rugoso, com diversos tipos de polimento, aplicações variadas de barbotina ou de engobes de diferentes consistências. Estas produções começaram no séc. III a. C. e atingiram o auge entre as últimas décadas do período tardo-republicano e o séc. I d.C., podendo, todavia, chegar até ao século IV d.C.. Os centros de fabrico mais antigos situam-se na Itália, mas a cerâmica de paredes finas foi também fabricada nas províncias a partir do reinado de Augusto. Assiste-se então a uma grande diversidade formal, que continua nos períodos de Tibério e Cláudio e até aos finais do século I a. C., data em que a produção diminui drasticamente, devido à concorrência dos vasos de beber fabricados em vidro. Na Hispânia as peças mais antigas provêm península itálica (em particular da Etrúria e do Vale do Pó), acompanhadas por outras cerâmicas com a mesma proveniência (i.e. sigillatas, lucernas, ânforas e cerâmicas de engobe vermelho), seguindo um circuito marítimo e fluvial. A partir dos finais do período de Augusto estas importaçôes vão sendo substituídas por produções peninsulares que se impóem nos mercados.

Além das baixelas finas de mesa faziam parte da vida diária das populações o uso de lucernas, geralmente fabricadas em argila (mas também, por vezes, em metal ou vidro), usadas na iluminação. Como no caso das sigillatas e das paredes finas acima referidas, as lucernas mais antigas que chegam à península são de origem itálica. Estas aparecem em contextos dos sécs. III a I a.C. e inspiram-se em modelos helenísticos. Caracterizam-se por possuir um reservatório pequeno e um bico comprido e direito, por vezes decorado com cabeças de ave, enquanto o disco é ornado com motivos vegetais, conchas ou pérolas. Na Hispânia (como de resto em todo o mundo romano) estas lucernas vão sendo substituídas no período de Augusto por exemplares com volutas no bico. Estas novas lucernas possuem um bico triangular ou arredondado e os discos exuberantemente decorados (em particular as do tipo Loeschcke I, var. a, b, c). Por vezes, as asas são substituídas por motivos em forma de folhas, máscaras, crescentes ou placas triangulares (Loeschcke III). A partir do século I d.C., os bicos são normalmente redondos, mais curtos, e desaparecem as volutas dando lugar às chamadas lucernas de disco (i.e. Dressel 20 e 28) e de canal (i.e. Loeschcke X), ainda que desta vez maioritariamente fabricadas em território peninsular. Na Hispânia a tradição de produção de lucernas perdura no período baixo-imperial, a par com algumas importações provenientes do norte de áfrica, em particular da região tunisina. À semelhança das cerâmicas de mesa (sigillatas e paredes finas) as lucernas são importantes para o estabelecimento da cronologia dos sítios que os arqueólogos escavam, mas também para identificar importações e mercados, sobretudo quando representam, no fundo externo, marcas de fabricante.

Uma outra categoria cerâmica presente nos contextos arqueológicos são as ânforas, contentores utilizados desde a mais alta antiguidade, para o transporte de vinho ou azeite, molhos e conservas várias (garum; muria; halec), cereais e frutos. As ânforas, como contentores de transporte de produtos sólidos ou líquidos, 
permitem inestimáveis informaçôes sobre a vida económica, social e até política dos habitantes do império romano. A maior parte parece ter sido fabricada nos (ou perto dos) locais de produção do conteúdo. Depois de vazias, as ânforas podiam ser destruídas. Em Roma, junto ao porto fluvial da cidade, o Monte Testaccio, com cerca de $50 \mathrm{~m}$ de altura, não é mais do que uma enorme acumulação de restos de ânforas, em grande parte hispânicas olearias do tipo Dressel 20, fabricadas no vale do Guadalquivir ${ }^{7}$. Na Hispânia as primeiras ânforas romanas datam dos finais do período republicano e destinavam-se maioritariamente ao transporte dos afamados vinhos itálicos (i.e. Dressel 1). Como as outras categorias cerâmicas de proveniência itálica acima analisadas, estas ânforas estão maioritariamente concentradas nas zonas costeiras da península e nas áreas interiores, beneficiárias dos cursos fluviais. Apesar de conhecermos produções tardo-republicanas de ânforas fabricadas na península anteriores aos meados do século I a.C., sabemos que a partir desta data a produção é intensificada, com particular destaque na província da Bética, conhecida por ter sido precocemente romanizada e possuir fortes tradições agrícolas e pesqueiras. Nesta província cabe destacar a região ao longo do vale do Bétis, entre Sevilha, Córdoba e Écija, em particular em torno da produção olearia organizada pelos mercatores olearii, difusores ou negotiatores, e as áreas costeiras andaluzas dedicadas ao fabrico de preparados piscícolas ${ }^{8}$.

Por fim, depois de distinguirmos algumas categorias de cerâmica fina (como a cerâmica campaniense e a terra sigillata) e outros grupos perfeitamente caracterizados como as lucernas e as ânforas, falta referirmo-nos às chamadas cerâmicas comuns. Estas produçôes abarcam uma grande diversidade de categorias de cerâmicas nem sempre fáceis de individualizar e que por vezes transcendem a mera classificação tipológica e funcional. A maior parte destinava-se a cobrir as necessidades de recipientes para comer, cozinhar, armazenar, transportar ou lavar; por vezes serviam ainda como mobiliário funerário. Como se poderá supor estas cerâmicas faziam parte da vida diária das populações e foram produzidas em praticamente todas as regiōes da Península em época romana. Apesar de se destinarem a mercados geralmente reduzidos, por vezes podiam integrar circuitos de dimensão considerável, como foi o caso das cerâmicas comuns de engobe vermelho pompeiano nos finais do período tardo-republicano e os inícios do período flávio e das cerâmicas comuns béticas de pasta calcária, datáveis do período imperial, que chegaram a mercados longínquos. Igualmente conhecidas são as produçôes de cerâmica comum africana que acompanharam o comércio das sigillatas africanas e das ânforas (para além do comércio de cerais). Hoje sabe-se,

${ }^{7}$ Mas as ânforas também podiam ser reutilizadas: encaixadas umas nas outras, serviam de condutas de água ou como armação de abóbadas; cortadas, serviam de sarcófagos de crianças ou mesmo como urnas cinerárias; quando fragmentadas serviam para serem reutilizadas em terraplanagens, na construção de muros e na preparação de opus signinum.

${ }^{8}$ Conhecem-se outros focos importantes de produção de ânforas situados em toda a zona costeira do levante espanhol e na costa portuguesa. 